\title{
Improving heart failure transitional care after hospital discharge: A quality improvement project
}

\author{
Janelle N. Akomah ${ }^{1}$, Lynn Richards-McDonald ${ }^{2}$, Diana-Lyn Baptiste*1 \\ ${ }^{1}$ School of Nursing, Johns Hopkins University, United States \\ ${ }^{2}$ The Johns Hopkins Hospital, United States
}

Received: May 15, 2020

DOI: $10.5430 /$ jnep.v10n11p62
Accepted: July 20, 2020

URL: https://doi.org/10.5430/jnep.v10n11p62

\begin{abstract}
Background and objective: The burden of heart failure is growing, affecting more than 6 million Americans and an estimated of 26 million worldwide. Heart failure is the most common cause of hospital readmission in the United States and is identified as a marker of poor health outcomes. Thirty day readmission contribute to more than $\$ 30$ billion dollars in health care expenditures, underscoring a need for the development and implementation of programs that reduce readmission and improve outcomes for individuals with heart failure. The purpose of this quality improvement project was to implement a heart failure education program to increase attendance to a transitional care clinic and reduce 30-day readmissions.

Methods: We included 22 individuals who received heart failure education, focused on symptom management and transitional care. Descriptive and statistical analyses were performed to examine attendance to the transitional care clinic and 30-day readmission.

Results: There was a statistical significance between individuals attending follow-up at the designated transitional care clinic and 30 -day hospital readmission $(p \leq .05)$. Of the $(\mathrm{N}=22)$ participants, $64 \%$ were not readmitted into the hospital 30 days after discharge.

Conclusions: The findings of this project demonstrate that a nurse-led evidence-based heart failure education program can improve attendance to transitional care programs and reduce 30-day readmissions. A well-designed plan for transitional care remains a critical component of patient care necessary to address complications and optimize continuity of care after discharge.
\end{abstract}

Key Words: Heart failure, Readmission, Patient education, Transitional care

\section{INTRODUCTION}

The global burden of heart failure is growing with an estimated distribution of 26 million adults living with heart failure worldwide. ${ }^{[1,2]}$ Heart failure is a burdensome condition, affecting more than 6 million Americans, contributing to 1 in 8 deaths in the US each year. ${ }^{[3]}$ The prevalence of heart failure continues to rise over time and is projected to increase $25 \%$ by 2030 , with $50 \%$ of patients having a 5 -year mortality rate from the time of initial diagnosis. ${ }^{[4-6]}$ Heart failure is defined as a condition in which the heart is incapable of pumping enough blood to meet the demand of the body. ${ }^{[7,8]}$ Heart failure can affect the right, left, or both sides of the heart of adults and children. Debilitating symptoms of heart failure include breathlessness, fluid retention, and chronic fatigue..$^{[7,9,10]}$

Heart failure hospitalizations are at the highest frequency in the United States among other morbidities accounting for an estimated $\$ 30.7$ billion in annual health care costs..$^{[1,3,11]}$

*Correspondence: Diana Lyn Baptiste; Email: dbaptis1@jhu.edu; Address: School of Nursing, Johns Hopkins University, United States. 
Heart failure is the most common cause of thirty day hospital readmission. ${ }^{[5,11]}$ Readmissions are preventable events and marker of poor health outcomes. ${ }^{[1]}$ These readmissions have a considerable economic impact as costs of the rehospitalization are exorbitant to insurance companies, medical institutions, and Medicare. ${ }^{[3,5,11]}$ The association between time from hospital discharge to outpatient follow-up with a physician and risk of readmission is related to severity of illness. ${ }^{[12,13]}$ Early follow-up and transitional care after in-patient hospital discharge is highly recommended to reduce readmissions and improve overall health outcomes for individuals with heart failure. ${ }^{[8,11,14]}$

Transitional care clinics are designed to ensure coordination and continuity in health care as patients transfer between locations. ${ }^{[13]}$ Individuals with heart failure who are transitioning from inpatient to outpatient care are extremely vulnerable because of complex regimen, comorbid conditions, and multiple clinicians involved in coordination of care. ${ }^{[14]}$ Transitional care clinics are designed to provide services to patients recently discharged from the hospital. Individuals who manage symptoms, make lifestyle modifications, and adhere to medication regimens will experience fewer emergency room visits, hospitalizations and improved quality of life. ${ }^{[15,16]}$ Transitional care clinics consists of a team of multidisciplinary teams of nurses, nurse practitioners, and cardiologists. The nursing staff reviews personal medical history with the patient, educates with tools of self-care (exercise and nutrition guidelines), on diet and fluid management techniques, appropriate time to attend the clinic versus the emergency department, and assists patients in identifying the signs and symptoms of heart failure.

\section{MethodS}

\subsection{Design, setting, and sample}

This quality improvement project was implemented from November 2014 to April 2015. The study was designed to answer the practice question: Does the use of a transitional care clinic reduce readmission among individuals with heart failure? The project was implemented in an urban academic medical center located in the Northeastern region of the United States on two cardiac/telemetry inpatient units in the department of medicine. The evaluation was based on visits to a transitional care clinic called the "Heart Failure Bridge Clinic", which shares the same physical location as the inpatient units in this center.

This convenience sample of $(\mathrm{N}=22)$ consisted of individuals that were discharged from the hospital and had a follow up appointment with the Heart Failure Bridge clinic within two weeks post-discharge. The group of individuals receiving the intervention included patients aged $\geq 18$ years old, admitted

Published by Sciedu Press to the hospital with a primary diagnosis of congestive heart failure and living within 50 miles of the Heart Failure Bridge Clinic per clinic policy. Excluded were individuals and those who lived more than 50 miles away from the medical center and those who have already received care at the Heart Failure Bridge Clinic prior to hospitalization. For this project there were two specific aims, 1) to improve attendance to the Heart Failure Bridge Clinic among patients with heart failure after hospital discharge, 2) evaluate impact of the Heart Failure Bridge Clinic on 30-day readmissions.

\subsection{Theoretical framework}

Nursing conceptual frameworks are developed to support implementation of evidence into nursing practice. ${ }^{[17,18]}$ For this project, it was important to select a framework that guided and reflected effective implementation of the intervention and analysis. The Iowa Model is used to facilitate the process of identifying the problem and developing a solution while incorporating evidence. ${ }^{[17]}$ Steps of the Iowa model include problem identification, forming a team, literature review, implementing change, and disseminating the findings. ${ }^{[17]}$

The first step in using the Iowa Model is to identify the problem commencing the need for change. ${ }^{[17]}$ The problem identified for the project was the lack of individuals following up with the Bridge clinic after hospital discharge. Once a problem was acknowledged by the principal implementer, a group was formed that included: the department of medicine heart failure resource nurse, director of nursing, capstone preceptor and mentor. This specific group formation represented the second step of the Iowa Model; team formation. ${ }^{[17]}$ Lack of education and awareness about the importance of followup appointments was acknowledged. The next steps in the Iowa Model are critique, review, and locate evidence supporting or refuting change to address the problem. ${ }^{[17]}$ Literature was reviewed using this process to support the decision of implementing the use of an informational brochure to educate and raise awareness in patients requiring follow-up with the Bridge clinic. A literature review is essential for application of evidence into practice. ${ }^{[18]}$ The implementation of the educational intervention with the inclusion of an informational brochure began and evaluation followed with the use of statistical and reflective information. Stakeholders of the project were contacted to assess recommendations and reception of the use of the brochure pending hospital discharge for HF patients.

\subsection{Intervention}

Twenty-two patients who met the inclusion criteria were recruited, and $100 \%$ enrolled in the program. Participants were provided with a one-on one heart failure education session 
and a post-discharge appointment date prior to leaving the hospital. The heart failure resource nurse conducted an inservice for the physicians and nurse practitioners focusing on the importance of scheduling appointments pre-discharge. Discharge teaching was provided per usual care, however, the participants were provided with additional education tools that included an infographic style educational brochure about the Heart Failure Bridge Clinic. The primary goal of the standardized education program was to promote awareness of the transitional care clinic as an available resource to individuals with heart failure after hospital discharge. Additional topics covered in the education program were symptom management, self-care, lifestyle modifications, and medication adherence. The brochure distributed included key recommendations from the 2017 American College of Cardiology Foundation and American Medical Association Guidelines of Management of Heart Failure (ACCF/AHA), the Heart Failure Bridge Clinic website, and American Heart Association resources. ${ }^{[1,8]}$

\subsection{Ethical considerations}

This quality improvement project was acknowledged by The Institutional Review Board/Office of Human Subjects. This project was categorized as non-human subjects research and received approval before data collection was initiated.

\subsection{Data collection and analysis}

Data collection was performed using chart review, using the electronic medical records at the Heart Failure Bridge clinic. Demographics collected of each patient included age, race, and gender. Participants were assigned a random numerical code for de-identification. Admission and discharge information was obtained from the hospital medical records department and the Heart Failure Bridge Clinic. There were no specific tools used for measurement of health failure knowledge, medication adherence or self-care.

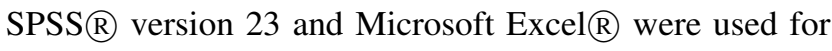
data collection and analyses. Statistical significance was determined with a two-sided alpha $(\alpha)$ of $<0.05$. Comparisons were made between clinic attendance rates and 30-day hospital readmission rates among the sample of participants. Descriptive statistics was used to summarize demographics among this sample. The primary outcome for this project was the attendance rate of the Heart Failure Bridge Clinic. The secondary outcome was measurement of the 30-day hospital readmission rate. The revised Standards for Quality Improvement Reporting Excellence (SQUIRE 2.0) guidelines, were used for reporting of the outcomes. ${ }^{[19]}$

\section{RESULTS}

As shown in Table 1, we included 22 participants that received the educational intervention along with additional instruction for transitional care using the standardized heart failure education brochure. Of the 22 participants, $59 \%$ were female and $41 \%$ male One participant was of Hispanic ethnicity, while fifty percent $(n=11)$ were African-American and 45 percent $(n=10)$ were White. Ages of participants ranged from $45-85$ years, with a mean of 64 years. Of the 22 participants who received the education intervention, eight were readmitted within 30-days of discharge while 14 were not readmitted within 30-days.

Table 1. Demographic characteristics of participants $(\mathrm{N}=$ 22)

\begin{tabular}{ll}
\hline & Mean/\% (SD) \\
\hline Gge & $64.4( \pm 10.1)$ \\
Male & $9(41 \%)$ \\
Female & $13(59 \%)$ \\
Race & \\
White & $10(45 \%)$ \\
African-American & $11(50 \%)$ \\
Hispanic & $1(4 \%)$ \\
\hline
\end{tabular}

An independent $t$-test performed to analyze statistical difference between patients that attended the Heart Failure Bridge Clinic, compared to those who did not attend. Among the 22 participants who received the educational session, $(\mathrm{n}=$ 16) attended their follow-up appointment, while $(\mathrm{N}=6) \mathrm{did}$ not attend, $(p \leq .05)$. Of the 16 participants who attended the follow-up, four (25\%) were readmitted, compared to $66 \%$ readmission among those who did not attend the followup (see Table 2). There was a significant difference ( $p \leq$ .05) between readmission rates among the groups who did or did not attend the Heart Failure Bridge Clinic follow-up appointments after hospital discharge.

Table 2. Heart Failure Bridge Clinic follow-up attendance and 30-day readmission rates

\begin{tabular}{llll}
\hline & Attendance/(\%) & $\begin{array}{l}\text { 30-day } \\
\text { readmission/(\%) }\end{array}$ & p value \\
\hline Attended & $16(73)$ & $4(25)$ & $<.05$ \\
Did not attend & $6(27)$ & $4(67)$ & \\
\hline
\end{tabular}

\section{Discussion}

The principal objective of the project was to determine the feasibility of using an educational program to increase patient attendance to the Heart Failure Bridge Clinic and examine 30-day readmissions. Our findings suggest that the 
implementation of a standardized heart failure educational program using an evidence-based infographic brochure can improve attendance to transitional care clinics. Furthermore, our results showed that those who attended the Heart Failure Bridge clinic appointments were less likely to be readmitted than those who did not (67\% vs. $25 \%$ ), respectively. Prior to the implementation of this program, attendance rate of the Heart Failure Bridge Clinic was obscure and at the time, had not been addressed since the inception of the clinic in 2012. The attendance rate among this small sample was $72 \%$ which demonstrated improvement from attendance rates before the implementation of this education program. Promoting awareness of the Heart Failure Bridge Clinic as an available resource was an essential component of this project as patients with chronic conditions are more likely to return to the same facility for other health care needs. ${ }^{[15]}$

The use of the evidence-based brochure proved to be an effective way to educate patients about effective use of transitional care after hospitalization for heart failure. The brochure was also effective in facilitating discussions between nurses and patients about heart failure medications, symptoms, and self-care. Although not measured in this project, literature supports the concept in which quality of life increases with outpatient follow up and that heart failure clinic process measures are associated with improved self-care and reduced hospital readmissions. ${ }^{[5,20,21]}$ This project was a low cost, efficient approach to addressing 30-day readmissions and outlined a simple but promising effort to engage patients in transitional care. This program demonstrates that evidencebased recommendations and materials can be tailored to serve a particular site or population. Most importantly, nurses can successfully lead and evaluate these initiatives in efforts to increase patient participation in transitional care. Previous studies have asserted that transitional care clinics can reduce the risk of unplanned admissions and are most effective with intensive appointments close to discharge. ${ }^{[16,22]}$ Moreover, research supports the use of evidence-based standardized education infographic brochures to assist patients in learning the importance of follow-up appointments, self-care, medication adherence, and preventable hospitalizations. ${ }^{[1,5,8,13]}$ However, there are very few studies reporting use of brochures for these purposes, underscoring the need to examine the best approach to promoting awareness of transitional care programs. This nurse-led initiative provided a feasible, costeffective approach to assisting patients in transitioning from the hospital and reduce readmission within 30 days. Effective care management post-hospital discharge is essential for the patient transitioning from the hospital to home.

\section{Limitations}

The authors acknowledge some limitations. This quality improvement was conducted using a small non-randomized convenience sample at a single site over a short time period; leading to poor generalizability. Other limitations to the project included the exclusion criteria applicable to many patients admitted to the hospital during implementation. Exclusion criteria comprised of patients previously aware of or attended the clinic prior to hospitalization. Furthermore, the effectiveness of the information provided in the brochure from the individualized face-to-face session with the patient and its contribution to enhancement of awareness was not measured.

\section{Conclusions}

A well-designed plan for transitional care remains a critical component of patient care necessary to improve postdischarge follow-up and reduce 30-day readmission. This project highlights the importance of a transitional care and how improving attendance to clinic follow-up can contribute to a reduction in 30-day hospital readmission rates. The implementation of projects that promote awareness transitional care presents a feasible a cost effective approach for enhancing patient care delivery. Nurses are uniquely qualified to implement such programs that can improve transitional care and need to accommodate evidence-based recommendations to practice settings across the globe.

\section{CONFLICTS OF INTEREST DisClOSURE}

The authors declare that there is no conflict of interest.

\section{REFERENCES}

[1] Benjamin EJ, Muntner P, Alonso A, et al. Heart Disease and Stroke Statistics-2019 Update: A Report From the American Heart Association. Circulation. 2019; 139(10): e56-e528.

[2] Virani SS, Alonso A, Benjamin EJ, et al. Heart Disease and Stroke Statistics-2020 Update: A Report From the American Heart Association. Circulation. 2020; 141(9): e139-e596. https ://doi .org/10 $.1161 /$ CIR. 0000000000000746
[3] Centers for Disease Control and Prevention, National Center for Health Statistics. Underlying Cause of Death, 1999-2017. Accessed January 7, 2019.

[4] Butler J, Kalogeropoulos A. Hospital strategies to reduce heart failure readmissions: where is the evidence? J Am Coll Cardiol. 60. United States. 2012. p. 615-7. PMid:22818073 https: //doi.org/10.1016/j.jacc.2012.03.066

[5] Awoke MS, Baptiste DL, Davidson P, et al. A quasi-experimental 
study examining a nurse-led education program to improve knowledge, self-care, and reduce readmission for individuals with heart failure. Contemporary Nurse. 2019; 1-12.

[6] Savarese G, Lund LH. Global Public Health Burden of Heart Failure. Card Fail Rev. 2017; 3(1): 7-11. https://doi.org/10.15420/c fr. 2016:25:2

[7] Asano R, Mathai SC, Macdonald PS, et al. Oxygen use in chronic heart failure to relieve breathlessness: A systematic review. Heart Fail Rev. 2020; 25(2): 195-205. PMid:31222538 https://doi or $\mathrm{g} / 10.1007 / \mathrm{s} 10741-019-09814-0$

[8] Yancy CW, Jessup M, Bozkurt B, et al. 2017 ACC/AHA/HFSA Focused Update of the 2013 ACCF/AHA Guideline for the Management of Heart Failure: A Report of the American College of Cardiology/American Heart Association Task Force on Clinical Practice Guidelines and the Heart Failure Society of America. J Card Fail. 2017; 23(8): 628-51

[9] Walthall H, Jenkinson C, Boulton M. Living with breathlessness in chronic heart failure: a qualitative study. J Clin Nurs. 2017; 26(1314): 2036-44. PMid:27731919 https ://doi .org/10.1111/jocn .13615

[10] Baptiste DL, Davidson P, Groff Paris L, et al. Feasibility study of a nurse-led heart failure education program. Contemporary Nurse. 2016; 52(4): 499-510. PMid:27575637 https://doi.org/10.1 $080 / 10376178.2016 .1229577$

[11] Jackson SL, Tong X, King RJ, et al. National Burden of Heart Failure Events in the United States, 2006 to 2014. Circ Heart Fail. 2018; 11(12): e004873. PMid:30562099 https ://doi.org/10.1161/ CIRCHEARTFAILURE. 117.004873

[12] Tung YC, Chang GM, Chang HY, et al. Relationship between Early Physician Follow-Up and 30-Day Readmission after Acute Myocardial Infarction and Heart Failure. PLoS One. 2017; 12(1): e0170061. PMid:28129332 https://doi.org/10.1371/journal.pone.0 170061

[13] Lee KK, Yang J, Hernandez AF, et al. Post-discharge Follow-up Characteristics Associated With 30-Day Readmission After Heart Failure Hospitalization. Med Care. 2016; 54(4): 365-72. PMid:26978568 https://doi.org/10.1097/MLR.0000000000000492

[14] Zsilinszka R, Mentz RJ, DeVore AD, et al. Acute Heart Failure: Alternatives to Hospitalization. JACC Heart Fail. 2017; 5(5): 329-36.
PMid:28285117 https://doi.org/10.1016/j.jchf .2016.12 .014

[15] Albert NM, Barnason S, Deswal A, et al. Transitions of care in heart failure: a scientific statement from the American Heart Association. Circ Heart Fail. 2015; 8(2): 384-409. PMid:25604605 https ://doi.org/10.1161/HHF.0000000000000006

[16] Albert NM. A systematic review of transitional-care strategies to reduce rehospitalization in patients with heart failure. Heart Lung. 2016; 45(2): 100-13. PMid:26831374 https://doi.org/10.101 6/j.hrtlng. 2015.12.001

[17] Doody CM, Doody O. Introducing evidence into nursing practice: using the IOWA model. Br J Nurs. 2011; 20(11): 6614. PMid:21727852 https://doi.org/10.12968/bjon.2011.2 0.11 .661

[18] Carter EJ, Mastro K, Vose C, et al. Clarifying the Conundrum: Evidence-Based Practice, Quality Improvement, or Research?: The Clinical Scholarship Continuum. J Nurs Adm. 2017; 47(5): 266-70. PMid:28422932 https ://doi.org/10.1097/NNA .0000000000 000477

[19] Ogrinc G, Davies L, Goodman D, et al. [SQUIRE 2.0 (Standards for QUality Improvement Reporting Excellence): Revised publication guidelines from a detailed consensus process]. Medwave. 2015; 15(10): e6318. PMid:26610177 https ://doi.org/10.5867/me dwave.2015.10.6318

[20] Gupta A, Fonarow GC. The Hospital Readmissions Reduction Program-learning from failure of a healthcare policy. Eur J Heart Fail 2018; 20(8): 1169-74. PMid:29791084 https://doi.org/10.1 $002 /$ ejhf. 1212

[21] Hole T, Grundtvig M, Gullestad L, et al. Improved quality of life in Norwegian heart failure patients after follow-up in outpatient heart failure clinics: results from the Norwegian Heart Failure Registry. Eur J Heart Fail. 2010; 12(11): 1247-52. PMid:20847014 https://doi .org/10.1093/eurjhf/hfq156

[22] Thomas R, Huntley A, Mann M, et al. Specialist clinics for reducing emergency admissions in patients with heart failure: a systematic review and meta-analysis of randomised controlled trials. Heart. 2013; 99(4): 233-9. PMid:23355639 https ://doi.org/10.1136/hear tjnl-2012-302313 